\title{
TrnH-psbA sequence analyses of asparagus cochinchinensis from different geographical origin in China
}

\author{
Yingzi Ma ${ }^{\mathrm{a}}$, Jialing Zhang and Jianghai Liu \\ College of Life Science and Technology, Central South University of Forestry and Technology, Changsha, Hunan \\ 410004, China
}

\begin{abstract}
This template explains and demonstrates how to prepare your camera-ready paper for The trnH-psbA sequences of 13 Asparagus cochinchinensis populations from 6 provinces of China were studied. The results showed that length of trnH-psbA change and the mutation of GC content were small. The length of trnH-psbA sequences were from 619 bp to $632 \mathrm{bp}$, and the GC content was about $36 \%$. The total variation rates of 13 populations were from $2.21 \%$ to $3.47 \%$, when the missing sites were considered as variation sites. A. cochinchinensis from different sources had 10 information sites in trnH-psbA sequence, accounting for $1.58 \%$ of the total sequence. The information sites were located in the sites $8,9,120,457,458,486,487$, 491, 492, and 593, respectively. Clustering analysis showed that the Qianxi and Hengshan populations clustered together; Dushan, Yuqing, and Guangzhou populations were grouped; Nanning and Xinning populations formed another cluster. trnH-psbA sequences could identify different A. cochinchinensis populations. Clustering of different A. cochinchinensis populations related primarily to latitude and had little relationship with longitude.
\end{abstract}

\section{Introduction}

Asparagus cochinchinensis (Lour.) Merr. belongs to Liliaceae -(or lily family). It is mainly produced in Guizhou, Yunnan, and Hunan provinces in China. Its roots have been used as a traditional Chinese herbal medicine to nourish 'YIN', clear lung, alleviate constipation, and cure antibacterial infection and cancer[1]. Current researches of A. cochinchinensis focused on its chemical composition, pharmacological effect, and clinical application. The previous studies showed that main components were carbohydrate[2,3], amino acids [4], and saponins [5]. Clinical applications have been conducted on hyperplasia of mammary glands [6], malignant lymphosarcoma [7,8], antitussive and expectorant[9], immunity[10], and anti-radiation [11]. While genomic sequence and genuine of this plant were few reported.

The external influence to cytoplasm is smaller than to the nucleus, and the cytoplasm is relatively conservative and reflects the evolutionary trend. TrnH-psbA fragment is one of chloroplast intergenic regions. It has $75 \mathrm{bp}$ conserved sequence at both ends of fragment which is easy to design primerswith

\footnotetext{
a Corresponding author:ma_yingzi@163.com

This work was financially supported by Hunan Provincial Science and Technology department (2013TZ2024), and the Research Program from Education Department of Hunan Province of China(2014, NO.199).
} 
good universality and high amplification success. Previous research showed trnH-psbA sequence could be used as DNA barcoding to identify plant $[12,13,14]$. In this study, the genetic polymorphisms and relationships of 39 individuals from 13 populations were evaluated by using trnH-psbA fragment in order to provide accurate identification information for germplasm resources of A. cochinchinensis.

\section{Materials and methods}

Total 13 populations, 3 individuals per populations, were collected from Guangdong, Guangxi, Guizhou, Hunan, Zhejiang, and Qinghaiprovince (Table 1). DNA was extracted according to the method described by Rogers and Bendic (1988).

Table 1. Source and location of A. cochinchinensis

\begin{tabular}{|c|c|c|c|c|}
\hline Location & $\begin{array}{c}\text { \# of } \\
\text { Sample }\end{array}$ & Source & \multicolumn{2}{|}{} \\
\cline { 4 - 5 } & & & Latitude( ${ }^{\mathbf{}}$ ) & Longitude( $^{\mathbf{}}$ ) \\
\hline Xining, Qinghai & 3 & Wild & 36.57 & 101.81 \\
\hline Hangzhou, Zhejiang & 3 & Cultivated & 29.18 & 118.35 \\
\hline Yanhe, Guizhou & 3 & Wild & 28.21 & 108.01 \\
\hline Hengshan, Hunan & 3 & Wild & 27.28 & 112.71 \\
\hline Qianxi, Guizhou & 3 & Wild & 26.90 & 105.68 \\
\hline Huaxi, Guizhou & 3 & Wild & 26.43 & 106.68 \\
\hline Xinning, Hunan & 3 & Wild & 26.25 & 110.30 \\
\hline Yuqing, Guizhou & 3 & Wild & 25.32 & 107.28 \\
\hline Dushan, Guizhou & 3 & Wild & 25.01 & 108.31 \\
\hline Yongzhou, Hunan & 3 & Wild & 24.65 & 111.00 \\
\hline Xingyi, Guizhou & 3 & Wild & 24.63 & 104.85 \\
\hline Guangzhou, Guangdong & 3 & Cultivated & 23.115 & 113.25 \\
\hline Nanning, Guangxi & 3 & Cultivated & 22.22 & 107.90 \\
\hline
\end{tabular}

The polymerase chain reactions (PCR) using trnH-psbA primerswere conducted according to Peterson [15 ]. The PCR products were fractionated on $1 \%$ agarose geland visualized using GelLogic 100 image system. The target fragments were isolated from the agarose gel under UV radiation, purified with the reagent kit (Tiangel midi purification kit), and then directly sequenced. Sequence analysis was performed by DNAMAN and MEGA 5.0.

\section{Results and discussion}

The trnH-psbA length of 39 samples was from 619 to $632 \mathrm{bp}$, and GC content was from $35.0 \%$ to $36.2 \%$ (Table 2). trnH-psbA sequences of 3 samples from a same population were almost the same and they only had few variable sites. Different populations had different variable sites.

Table 2. Length and GC content of trnH-psbA sequences

\begin{tabular}{|c|c|c|c|c|c|}
\hline Location & $\begin{array}{c}\text { Length } \\
\text { bp }\end{array}$ & $\begin{array}{c}\text { G C content } \\
\mathbf{\%}\end{array}$ & Location & $\begin{array}{c}\text { Length } \\
\text { bp }\end{array}$ & $\begin{array}{c}\text { G C content } \\
\mathbf{\%}\end{array}$ \\
\hline Xining & 621 & 35.6 & Yuqing & 620 & 36.0 \\
\hline Hangzhou & 620 & 36.0 & Dushan & 620 & 36.0 \\
\hline
\end{tabular}




\begin{tabular}{|c|c|c|c|c|c|}
\hline Yanhe & 621 & 35.8 & Yongzhou & 619 & 36.2 \\
\hline Hengshan & 621 & 35.9 & Xingyi & 621 & 36.1 \\
\hline Qianxi & 621 & 35.7 & Guangzhou & 620 & 35.8 \\
\hline Huaxi & 632 & 35.0 & Nanning & 621 & 36.1 \\
\hline Xinning & 621 & 36.1 & & & \\
\hline
\end{tabular}

The loss rates were about $2.00 \%$ except Huaxi population that was $0.32 \%$. Mutational rates were from 0 to $2.52 \%$. Yuqing population had no mutations, while Huaxi population had the highest mutational rate, $2.52 \%$. The total mutational rates ranged from $2.21 \%$ to $3.47 \%$ when a vacancy was counted as a mutational site. Xingyi population had the hightest mutational rate of $3.47 \%$, and Yuqing population had the lowest mutational rate of $2.21 \%$ (Table 3 ).

Table 3. The loss and mutational rate of different populations

\begin{tabular}{|c|c|c|c|c|c|c|c|}
\hline Populations & $\begin{array}{c}\text { Loss } \\
\text { rate }\end{array}$ & $\begin{array}{c}\text { Mutational } \\
\text { rate }\end{array}$ & Total & Populations & Loss rate & $\begin{array}{c}\text { Mutational } \\
\text { rate }\end{array}$ & Total \\
\hline Xining & 2.05 & 0.95 & 3.00 & Yuqing & 2.21 & 0.00 & 2.21 \\
\hline Hangzhou & 2.21 & 0.63 & 2.84 & Dushan & 2.21 & 0.32 & 2.53 \\
\hline Yanhe & 2.05 & 0.32 & 2.37 & Yongzhou & 2.37 & 0.32 & 2.69 \\
\hline Hengshan & 2.05 & 0.47 & 3.52 & Xingyi & 2.05 & 1.42 & 3.47 \\
\hline Qianxi & 2.05 & 0.32 & 2.37 & Guangzhou & 2.21 & 0.16 & 2.37 \\
\hline Huaxi & 0.32 & 2.52 & 2.84 & Nanning & 2.05 & 0.32 & 2.37 \\
\hline Xinning & 2.05 & 0.32 & 2.37 & & & & \\
\hline
\end{tabular}

There were 10 information sites which were single nucleotide sites (SNPs). When a vacancy as an absence in different populations from different provinces were at positions 8, 9, 120, 457, 458, 486, 487, 491, 492 and 593. They were transition at positions 492 and 593, transversion at positions 8,120, 486,487 and 491 (Table 4).

Table 4. trnH-psbA sequences information sites of different provinces

\begin{tabular}{|c|c|c|c|c|c|c|c|c|c|c|}
\hline \multirow{2}{*}{ Origin } & \multicolumn{9}{|c|}{ Information site } \\
\cline { 2 - 13 } & $\mathbf{8}$ & $\mathbf{9}$ & $\mathbf{1 2 0}$ & $\mathbf{4 5 7}$ & $\mathbf{4 5 8}$ & $\mathbf{4 8 6}$ & $\mathbf{4 8 7}$ & $\mathbf{4 9 1}$ & $\mathbf{4 9 2}$ & $\mathbf{5 9 3}$ \\
\hline Guizhou Province & $\mathrm{C}$ & $\mathrm{A}$ & $\mathrm{A}$ & $\mathrm{A}$ & - & $\mathrm{A}$ & $\mathrm{G}$ & $\mathrm{G}$ & $\mathrm{C}$ & $\mathrm{A}$ \\
\hline Guangxi Province & $\mathrm{C}$ & $\mathrm{A}$ & $\mathrm{G}$ & $\mathrm{A}$ & - & $\mathrm{A}$ & $\mathrm{G}$ & $\mathrm{G}$ & $\mathrm{C}$ & $\mathrm{T}$ \\
\hline Guangdong Province & $\mathrm{A}$ & - & $\mathrm{A}$ & $\mathrm{A}$ & - & $\mathrm{A}$ & $\mathrm{G}$ & $\mathrm{G}$ & $\mathrm{C}$ & $\mathrm{A}$ \\
\hline Hunan Province & $\mathrm{C}$ & $\mathrm{A}$ & $\mathrm{G}$ & $\mathrm{A}$ & - & $\mathrm{A}$ & $\mathrm{G}$ & $\mathrm{G}$ & $\mathrm{C}$ & $\mathrm{T}$ \\
\hline Zhejiang Provinc & $\mathrm{C}$ & $\mathrm{A}$ & $\mathrm{G}$ & - & - & $\mathrm{A}$ & $\mathrm{G}$ & $\mathrm{G}$ & $\mathrm{C}$ & $\mathrm{T}$ \\
\hline Qinghai Province & $\mathrm{A}$ & - & $\mathrm{A}$ & $\mathrm{A}$ & $\mathrm{A}$ & $\mathrm{G}$ & $\mathrm{A}$ & $\mathrm{A}$ & $\mathrm{G}$ & $\mathrm{A}$ \\
\hline
\end{tabular}

Note: “-":absence

UPGMA (unweighted pair-group method with arithmetic means) dendrogram based trnH-psbA sequences showed that the populations were divided into two branches. One included Yuqing, Guangzhou, Dushan, Xining, Qianxi, Hengshan, Yongzhou, and Huaxi populations, the other consisted of Hangzhou, Xingyi, Yanhe, Nanning, and Xinning. Yuqing, Guangzhou, and Dushan populations made a subgroup, while Xining, Qianxi, and Hengshan populations in another subgroup Xingyi and Yanhe population clustered, and Nanning and Xinning populations firstly clustered in the 
second branch. Guangzhou and Dushan populations were closer clustering although their latitudes had large distance (Figure 1).

There was a certain relationship between phylogenetic distribution of plants and the general geographic location (especially the latitude) $[16,17]$. This paper showed interspecific variation and phylogenetic distances of A. cochinchinensis mainly affected by latitude based the populations had closer relatives those had closer latitude with the analyse of trnH-psbA sequences that was consistent the results using ITS sequences [18]. Such as the similarity of the Qianxi and Hengshan populations was $99.8 \%$ with the latitude of the Qianxi populations was $27.28 \mathrm{~N}$ and Hengshan population was $27.05 \mathrm{~N}$, the similarity of the Huaxi and Yongzhou populations was $99.2 \%$ with the latitude of theHuaxi populations was $26.43 \mathrm{~N}$ and Yongzhou population was $26.13 \mathrm{~N}$. But there are some exceptions, the similarity of the Yuqing and Dushan populations was $99.7 \%$ while the latitude of the Yuqing populations was $22.50 \mathrm{~N}$ and Dushan population was $35.80 \mathrm{~N}$, this showed that the latitude may be factors on affecting the distribution of plant, but not the decisive factor. The populations from Guangzhou were firstly clustering with Dushan and Yuqing, Hangzhou were firstly clustering with Xingyi and Nanning were firstly clustering with Xinning, and they were cultivated populations, it indicated these populations might be introduced from Guizhou, Guizhou and Hunan Province, respectively

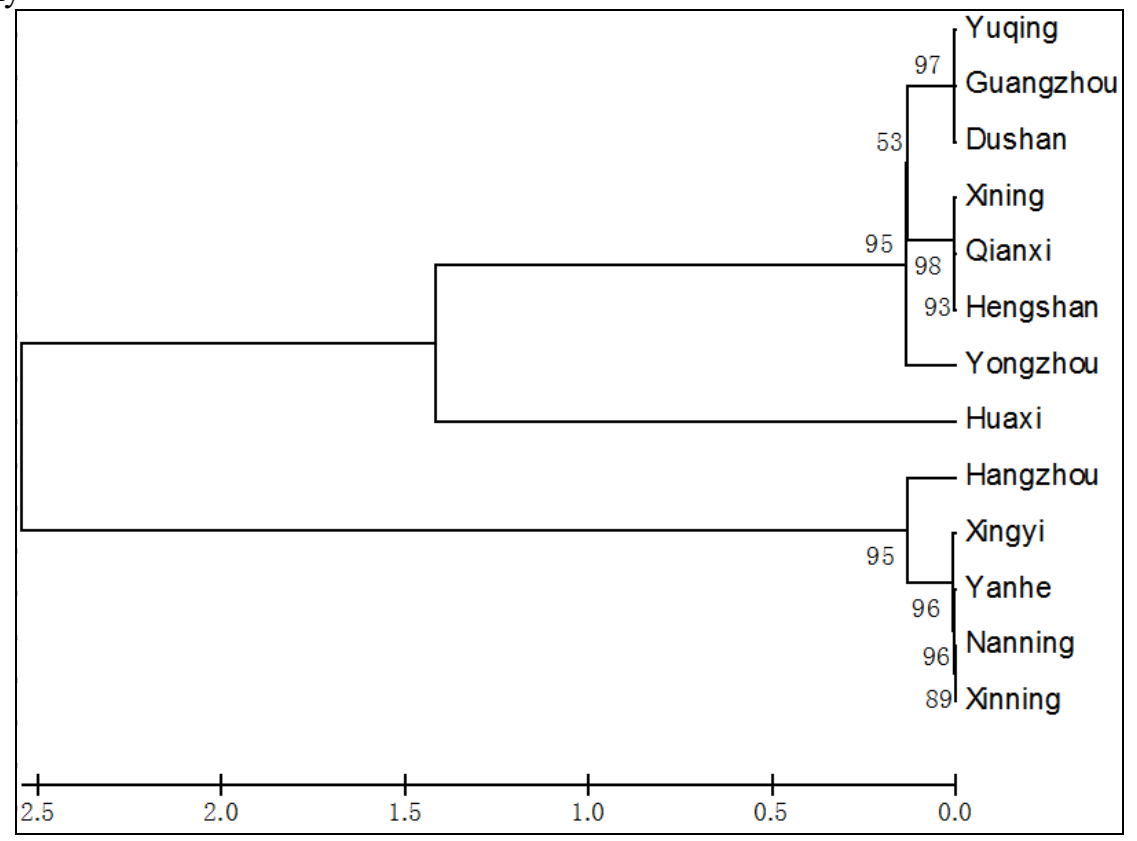

Figure 1. UPGMA homologous tree of A. cochinchinensis based trnH-psbA sequences

\section{Conclusion}

Wild A. cochinchinensis were mainly used and wild resources were gradually depleted with demand growing in recent years, we must rely on artificial cultivation and cultivated varieties mainly introduced by the off-site. An important feature of Chinese medicine was genuine, different local production of medicines had different active ingredients and content, so the genuineness of $A$. cochinchinensis medicine was important prerequisite to guide the introduction and selective improved variety. DNA sequence analysis was effective means to identify genuineness of medicinal materials. Our results showed the populations from Guizhou province had more genetic polymorphism based their trnH-psbA had more mutation rate, it suggested Guizhou province might be a genuine producing area, trnH-psbA sequence might clarify its genetic background from the molecular level to overcome 
varietal complexity induced the decline of yield and quality degradation and guide introduction and cultivation of $A$. cochinchinensis.

\section{References}

1. Yao NH, Kong NY. Developments of chemical compositions and biological action of asparagus L. Nat.l Prod. Res. Deve. Vol.11(1999), p. 67-71.

2. Du XH, Guo YZ. Studies on the isolation of antitumor active constituents of polysaccharides from Chinese herb asaragus cochinchinensis(Lour.) merr. Shenyang Phar. Univ. Vol.7(1990), p.197-201.

3. Li ZX, Huang CG, Cai YJ, Chen XM, Wang F, Chen YZ. The chemical structure and anttoxidative activity of polysaccharide from Asparagus cochinchinensis. Acta Phar. Sin. Vol.35(2000), p. 358-362.

4. Ni JM, Zhao NN, Wang R. Comparison of amino acid of Asparagus before and after processing. Chin. Trad. Herb. Drug. Vol.23(1992), p. 182.

5. Liang ZZ, Aquino R, De Simone F, Dini A, Schettino O, Pizza C. Oligofurostanosides from Asparagus cochinchinensis L. Planta Med., Vol. 54(1988), p. 344-346.

6. Shen ZY, Ping JL. 513 cases on hyperplasia of mammary glands with tamoxifen and asparagine. Clin. Med. Chin. Vol.13(1997), p. 138-139.

7. Xu L, Lao LX, Ge A, Yu S, Li J, Mansky PJ. Chinese herbal medicine for cancer pain. Integr. Cancer Ther. Vol.6 (2007), p. 208-234.

8. Zhang HJ, Sydara K, Tan G-T, Ma C-Y, Southavong B, Soejarto DD, Pezzuto JM, Fong HYS. Bioactive constituents from Asparagus cochinensis L. J Nat Prod. Vol.67(2004), p. 194-200.

9. Luo J, Long QD, Li CX, Li L, Huang NH, Nie M. Comparison of antitussive, expectorant and anti-asthmatic effect between ALWB and ACM. J. Guiyang Med. Coll. Vol.23(1998), p. 132-134.

10. Kumari R, Tiwary BK, Prasad A, Ganguly S.. Study on the immuno- modulatory effect of herbal extract of Asparagus racemosus Willd. in broiler chicks. Global J. Res. Medi. Pl. \& Indigenous Medi, Vol. 1(2011), p. 1-5.

11. Li QS, Li YJ, Liu Y. Protective effect and mechanism of Chinese Asparagus on damaged rat's heart induced by chronic radiation. Chin. J. Trad. Chin. Med. Pharm . Vol. 26(2011), p. 375-377.

12. Kress WJ, Wurdack KJ, Zimmer EA, Weigt LA, Janzen DH. Use of DNA barcodes to identify flowering plants. PNAS, Vol.( 2005)102, p. 8369-8374.

13. Nomura N, Takaso T, Peng CI, Kono Y, Oginuma K, Mitsui Y, Setoguchi H .Molecular phylogeny and habitat diversification of the genus Farfugium (Asteraceae) based on nuclear rDNA and plastid DNA. Ann. Bot., Vol.106(2010), p, $467-482$.

14. Shaw J, Lickey EB, Schilling EE, Small RL. Comparison of whole chloroplast genome sequences to choose noncoding regions for phylogenetic studies in angiosperms: the tortoise and the hare III . Amer. J.Bot., Vol.94(2007), p. 275-288.

15. Peterson, John H, Koch E, Peterson J. . A molecular phylogeny of the genus Gagea (Liliaceae) in Germany inferred from non- coding chloroplast and nuclear DNA sequences . Plant Syst. Evol., Vol.245(2004), p. 145-162.

16. Zhu SH, Zhang QF, Wang MQ. Ribosomal DNA polymorphisms of the common wild rice from China. Acta Gene. Sin. Vol.25(1998), p. 531-537.

17. Wang YH, Wang H, Gao LZ. Study on genetic diversity of Oryza rufipogon Griff. by simple seqence repeat. Acta Bot. boreali-occidentalia Sin. Vol.23(2003), p. 1750-1754.

18. Ou LJ, Zhang RW, Tan ZW, et al.. Nuclear DNA ITS sequence analysis of Asparagus cochinchinensis from different geographical regions in China. Chin. Trad. Herb. Drugs. Vol.42(2011), p. 1402-1406. 